\title{
Erratum to: Multicenter Institutional Experience of Surgically Resected Thymic Epithelial Tumors (TETs): An Observational Report on Behalf of F.O.N.I.C.A.P. (Forza Operativa Nazionale Interdisciplinare Contro il Cancro del Polmone)
}

Giovenzio Genestreti, MD¹, Luca Ampollini, $\mathrm{MD}^{2}$, Marco Angelo Burgio, $\mathrm{MD}^{3}$, Luigi Rolli, $\mathrm{MD}^{2}$, Stefano Sanna, $\mathrm{MD}^{4}$, Emanuela Scarpi, MSc ${ }^{5}$, Manuela Monti, $\mathrm{BSc}^{5}$, Salvatore Luca Burgio, $\mathrm{MD}^{3}$, Luciana Giannone, $\mathrm{BSc}^{6}$, Antonio Santo, $\mathrm{MD}^{6}$, Maurizio Mezzetti, $\mathrm{MD}^{7}$, Claudia Casanova, $\mathrm{MD}^{8}$, Roberta Buosi, $\mathrm{MD}^{9}$, Michele Rusca, $\mathrm{MD}^{2}$, Dino Amadori, $\mathrm{MD}^{3}$, and Giampaolo Gavelli, $\mathrm{MD}^{10}$

${ }^{1}$ Department of Clinical Oncology, Cervesi Hospital, Cattolica, RN, Italy; ${ }^{2}$ Department of Thoracic Surgery, University Hospital, Parma, Italy; ${ }^{3}$ Department of Medical Oncology, IRCCS Istituto Scientifico Romagnolo per lo Studio e la Cura dei Tumori (IRST-IRCCS), Meldola, Italy; ${ }^{4}$ Department of Thoracic Surgery, Morgagni-Pierantoni Hospital, Forlì, Italy; ${ }^{5}$ Unit of Biostatistics and Clinical Trials, IRST-IRCCS, Meldola, Italy; ${ }^{6}$ Department of Medical Oncology, University Hospital, Verona, Italy; ${ }^{7}$ Department of Thoracic Surgery, S. Carlo Borromeo Hospital, Milan, Italy; ${ }^{8}$ Department of Medical Oncology, Santa Maria delle Croci Hospital, Ravenna, Italy; ${ }^{9}$ Department of Clinical Oncology, Maggiore della Carità Hospital, Novara, Italy; ${ }^{10}$ Radiology Unit, IRST-IRCCS, Meldola, Italy

ERRATUM TO: ANN SURG ONCOL DOI 10.1245/S10434-013-3018-2

The correct name of the eighth author is Salvatore Luca Burgio.

The online version of the original article can be found under doi:10.1245/s10434-013-3018-2.

(C) Society of Surgical Oncology 2013

Published Online: 11 June 2013

G. Genestreti, MD

e-mail: ggenestreti@libero.it 